\title{
The most compatible position of operator for mandibular right posterior teeth extraction
}

\author{
Ramesh Kumaresan, Sivakumar Pendyala, Jawahar Dhanavel \\ Academic Unit of Craniofacial Clinical Care, AIMST University, Faculty of Dentistry, Kedah 08100, Malaysia.
}

Correspondence Author: Dr. Ramesh Kumaresan, Academic Unit of Craniofacial Clinical Care, AIMST University, Faculty of Dentistry, Jalan Semeling-Bedong, Kedah 08100, Malaysia. E-mail: rame1264@gmail.com

Sir,

The positions of the dental chair, patient and operator are critical for successful completion of tooth extraction. ${ }^{[1]}$ Whilst, the proper positioning of the operator is very important to have good visibility and accessibility of the oral cavity, besides allowing the surgeon to have maximal control of the force that is being delivered to the patient's tooth through the forceps. ${ }^{[1]}$ Also, proper operating position and good posture reduces fatigue and physical strain and possibility of developing musculo-skeletal disorders.

For extraction of the mandibular right posterior teeth, a right-handed operator would usually stand at the right rear position (11 o'clock) or direct rear position ${ }^{[2]}$ (12 o'clock) [Figure 1]. These positions give good visibility and maximal accessibility to the oral cavity posteriorly as far as right first mandibular molar. However, a diminished accessibility is experienced by many operators when extracting the right second and third molars from these positions. It also results in unnecessary curvature of the spine or slumping of shoulders during the surgical procedure leading to physical strain [Figure 2].

With the intention to overcome this diminished accessibility and to enhance the effectiveness of the operator, the authors recommend positioning of a right-handed operator at the

\begin{tabular}{|l|l|}
\hline \multicolumn{2}{|c|}{ Access this article online } \\
\hline Quick Response Code: & Website: \\
\hline & http:/www.parjournal.net \\
\cline { 2 - 3 } & \\
\hline
\end{tabular}

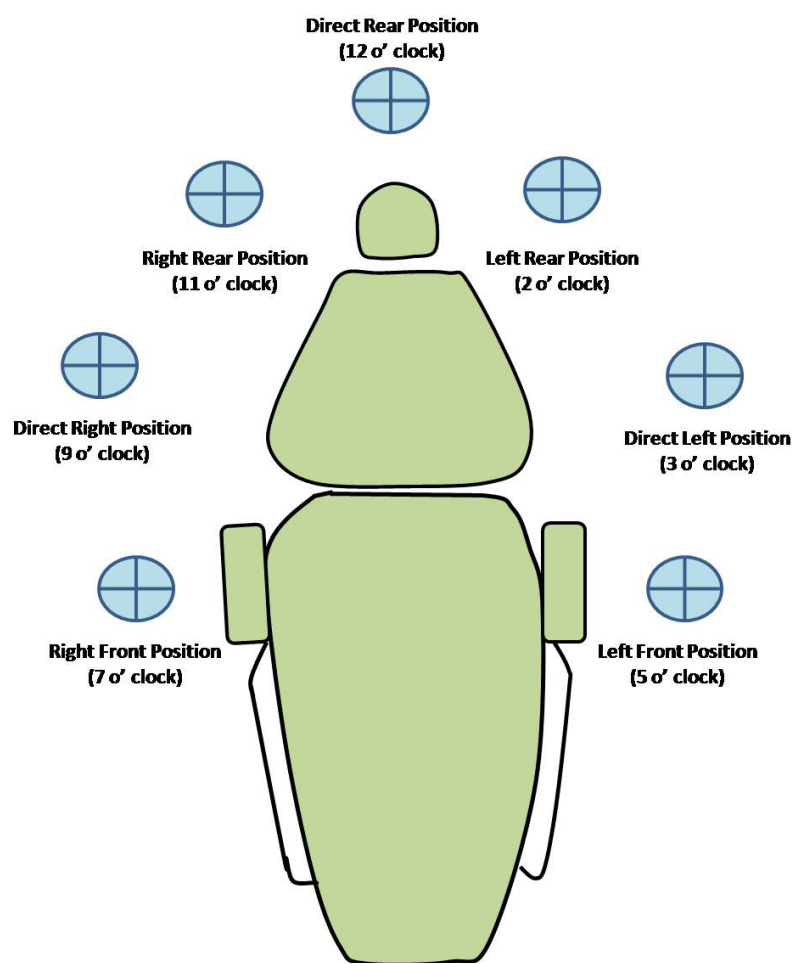

Figure 1: Operator positions for tooth extraction

left rear position (2 o'clock) for extraction of the mandibular right posterior teeth [Figure 3]. This compatible operator

This is an open access article distributed under the terms of the Creative Commons Attribution-NonCommercial-ShareAlike 3.0 License, which allows others to remix, tweak and build upon the work non-commercially, as long as the author is credited and the new creations are licensed under the identical terms.

For reprints contact: service@oaepublish.com

How to cite this article: Kumaresan $R$, Pendyala $S$, Dhanavel J. The most compatible position of operator for mandibular right posterior teeth extraction. Plast Aesthet Res 2016;3:257-8.

Received: 09-02-2016; Accepted: 07-06-2016 


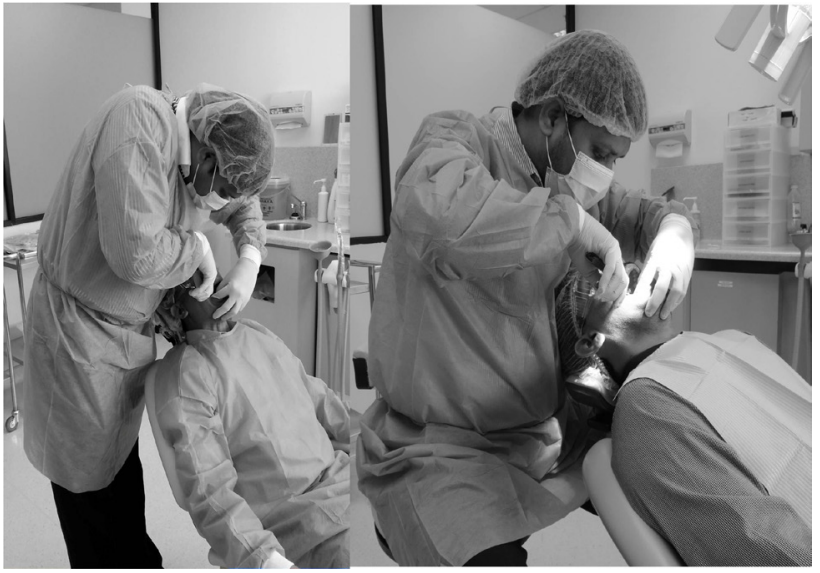

Figure 2: Diminished visibility and accessibility during extraction of mandibular right posterior teeth from right rear position

position provides a more balanced posture with increased visibility and accessibility to the oral cavity when extracting the mandibular right second and third molars.

\section{Financial support and sponsorship} Nil.

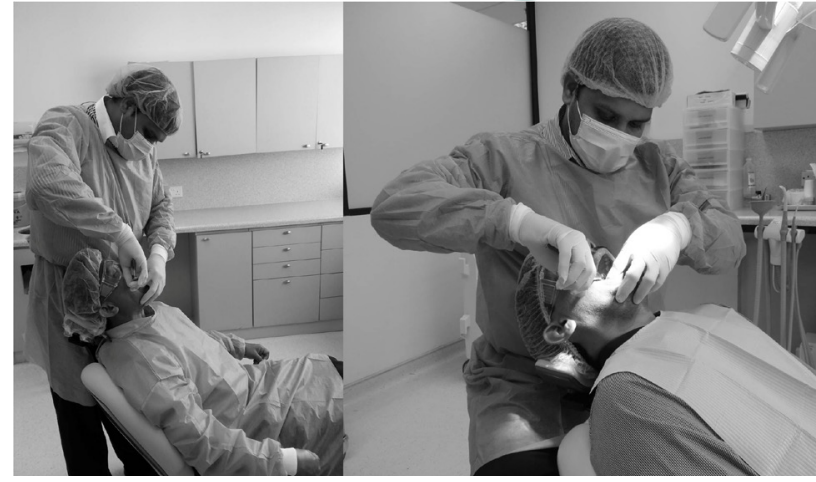

Figure 3: The most compatible operator position for mandibular right posterior teeth extraction

\section{Conflicts of interest}

There are no conflicts of interest.

\section{REFERENCES}

I. Hupp JR. Principles of Routine Exodontia. In: Hupp JR, Ellis E, Tucker MR, editors. Contemporary Oral and Maxillofacial Surgery. 6th ed. St Louis, Missouri: Mosby Elsevier; 20I4. p. 88-I I8.

2. Robinson PD. Tooth Extraction: a practical guide. Ist ed. Oxford: Wright; 2000. p. 34-5. 